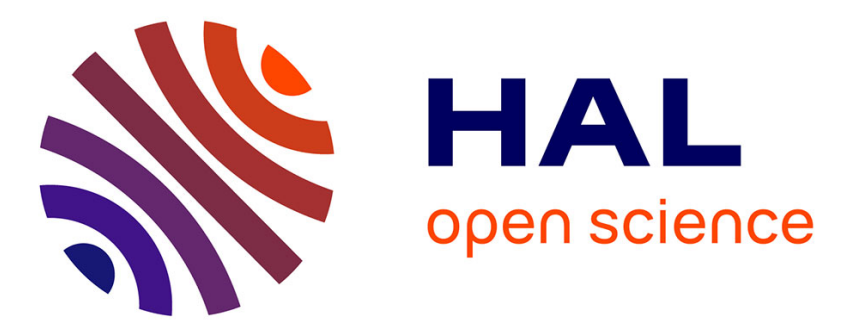

\title{
Cholecystokinin knock-down in the basolateral amygdala has anxiolytic and antidepressant-like effects in mice
}

\author{
C. del Boca, P.E. Lutz, J. Le Merrer, P. Koebel, B.L. Kieffer
}

\section{To cite this version:}

C. del Boca, P.E. Lutz, J. Le Merrer, P. Koebel, B.L. Kieffer. Cholecystokinin knock-down in the basolateral amygdala has anxiolytic and antidepressant-like effects in mice. Neuroscience, 2012, 218, pp.185-195. 10.1016/j.neuroscience.2012.05.022 . hal-02437990

\section{HAL Id: hal-02437990 https://hal.science/hal-02437990}

Submitted on 14 Jan 2020

HAL is a multi-disciplinary open access archive for the deposit and dissemination of scientific research documents, whether they are published or not. The documents may come from teaching and research institutions in France or abroad, or from public or private research centers.
L'archive ouverte pluridisciplinaire $\mathbf{H A L}$, est destinée au dépôt et à la diffusion de documents scientifiques de niveau recherche, publiés ou non, émanant des établissements d'enseignement et de recherche français ou étrangers, des laboratoires publics ou privés. 


\title{
Cholecystokinin knock-down in the basolateral amygdala has anxiolytic and antidepressant-like effects in mice
}

\author{
C Del Boca ${ }^{1}$, PE Lutz ${ }^{1}$, J Le Merrer ${ }^{1}$, P Koebel $^{1}$, and BL Kieffer ${ }^{1}$ \\ ${ }^{1}$ Institut de Génétique et de Biologie Moléculaire et Cellulaire (IGBMC), Centre National de \\ Recherche Scientifique/Institut National de la Santé et de la Recherche Médicale/Université de \\ Strasbourg, Illkirch-Graffenstaden, France
}

\section{Abstract}

Cholecystokinin (CCK) is a neuropeptide widely distributed in the mammalian brain. This peptide regulates many physiological functions and behaviors, such as cardio-respiratory control, thermoregulation, nociception, feeding, memory processes and motivational responses, and plays a prominent role in emotional responses including anxiety and depression. CCK-expressing brain regions involved in these functions remain unclear and their identification represents an important step towards understanding CCK function in the brain. The basolateral amygdala is strongly involved in emotional processing and expresses high levels of CCK. In this study we examined the contribution of CCK expressed in this brain region to emotional responses in mice. To knockdown CCK specifically in the basolateral amygdala, we used stereotaxic delivery of recombinant adenoassociated viral vectors expressing a CCK-targeted shRNA. This procedure efficiently reduced CCK levels locally. shCCK-treated animals showed reduced levels of anxiety in the elevated plusmaze, and lower despair-like behavior in the forced swim test. Our data demonstrate that CCK expressed in the basolateral amygdala represents a key brain substrate for anxiogenic and depressant effects of peptide. The study also suggests that elevated amygdalar CCK could contribute to panic and major depressive disorders that have been associated with CCK dysfunction in humans.

\section{Keywords}

Cholecystokinin; Baso-lateral Amygdala; depression; anxiety; adeno-associated viral vector; short-hairpin RNA

\section{Introduction}

Cholecystokinin (CCK), first identified as a gastrointestinal hormone (Mutt and Jorpes, 1968), is also highly expressed within the brain (Meziane et al., 1997). Neural CCK has been implicated in a wide range of physiological processes such as emotional and motivational states, thermoregulation, nociception and cognition (Beinfeld, 2001). Pre-proCCK is cleaved in smaller biologically active fragments acting as neuromodulatory peptides (Rotzinger et al, 2010). CCK peptides activate two closely related G-protein coupled

\footnotetext{
C 2012 IBRO. Published by Elsevier Ltd. All rights reserved.

Corresponding author: Pr. Brigitte L KIEFFER, IGBMC, Parc d'innovation 1 rue Laurent, Fries BP 10142, 67404 Illkirch Cedex, France, Phone: +33 (0)8 6556 93, Fax: +33 (0)8 6556 04, briki@igbmc.fr.

Publisher's Disclaimer: This is a PDF file of an unedited manuscript that has been accepted for publication. As a service to our customers we are providing this early version of the manuscript. The manuscript will undergo copyediting, typesetting, and review of the resulting proof before it is published in its final citable form. Please note that during the production process errors may be discovered which could affect the content, and all legal disclaimers that apply to the journal pertain.
} 
receptors, $\mathrm{CCK}_{1}\left(\mathrm{CCK}_{1}-\mathrm{R}\right)$ and $\mathrm{CCK}_{2}\left(\mathrm{CCK}_{2}-\mathrm{R}\right)$, the latter being predominant in the brain (Noble et al, 1999).

In human, high levels of CCK have been associated with motivational loss and panic disorders (Hebb et al, 2005), and a role for CCK has been proposed in the induction of anxiety and depression (Shindo and Yoshioka, 2005, Berna et al, 2007), with $\mathrm{CCK}_{2}-\mathrm{R}$ being the main effector of CCK anxiogenic properties (Bradwejn and Koszycki, 2001, Eser et al, 2011). In rodents, $\mathrm{CCK}_{2}-\mathrm{R}$ agonists increase levels of anxiety-like responses in several behavioral paradigms (Rotzinger et al, 2010), while conversely systemic $\mathrm{CCK}_{2}-\mathrm{R}$ antagonists attenuate stress-induced anxiety-like behavior (Wang et al., 2011). In addition, $\mathrm{CCK}_{2}-\mathrm{R}$ antagonists show antidepressant-like properties: systemic injection of a $\mathrm{CCK}_{2}-\mathrm{R}$ antagonist decreased behavioral despair in the forced swim test, and this effect was synergistic with the activity of the enkephalinase inhibitor RB101 (Hernando et al., 1996). Furthermore, chronic blockade of $\mathrm{CCK}_{2}-\mathrm{R}$ normalized hypothalamic-pituitary-adrenal axis hyperactivity and normalized the increase in despair-like behavior elicited by repeated social defeat (Becker et al, 2008). Concordant with pharmacological studies, genetic approaches (Noble and Roques, 2002) reveal that $\mathrm{CCK}_{2}-\mathrm{R}$ knock-out (KO) mice display decreased levels of anxiety (Raud et al, 2005). Moreover, transgenic mice over-expressing $\mathrm{CCK}_{2}-\mathrm{R}$ showed increased anxiety, as well as prolonged HPA axis activity following acute stress (Chen et al, 2010). Finally, antagonistic interactions between CCK and opioid systems have been established in the modulation and expression of stress-related behaviors, opposing memory-enhancing and anxiogenic effects of CCK to amnesic and anxiolytic effects of opioid peptides (Hebb et al,2005). These data also implicate CCK in reward, motivation and addictive behaviors (Lu et al, 2002, Pommier et al, 2002, Mitchell et al, 2006).

CCK and CCK-Rs are widely distributed throughout the rodent brain and may modulate emotional behaviors at several brain sites, notably in olfactory bulb, cerebral cortex, hippocampus, amygdala, thalamus and ventral tegmental area (Meziane et al, 1997, Cain et al, 2003). The amygdalar complex is implicated in the generation of emotional states, stress coding and associative learning (LeDoux, 2000), as well as retrieval of aversive memories (Frenois et al, 2005). In rat, local pharmacological studies have suggested a role for $\mathrm{CCK}_{2}-\mathrm{R}$ in the basolateral amygdala (BLA) in anxiogenic effects of CCK (Belcheva et al, 1994, Frankland et al., 1997). To our knowledge however, the role of CCK expressed in the BLA has not been investigated by genetic approaches. In the present study, we used a siRNAbased strategy to locally knock-down CCK. We injected in the BLA a recombinant viral vector encoding a shRNA targeting CCK and then examined behavioral consequences on emotional responses.

\section{Experimental Procedures}

\section{1 $A A V_{2}$ viral vectors construction}

A short hairpin (sh) RNA was designed to target the mcck gene (5'TCAGTGACTCCCAGACCTAATGTT-3'). Recombinant AAV ${ }_{2}$-shCCK viral vectors were generated expressing eGFP and shCCK $\left(\mathrm{AAV}_{2}\right.$-shCCK) under the control of CMV and mU6 promoters respectively. Control vectors encode either for eGFP alone ( $\mathrm{AAV}_{2}$-eGFP) or for eGFP and a scramble shRNA ( $\mathrm{AAV}_{2}$-shScramble). The shScramble sequence selected (5'-GTTGGCTCCTAGCAGATCCTA-3 ${ }^{\prime}$ ) has no match in silico in the mouse genome. $\mathrm{AAV}_{2}$ vectors were generated by triple transfection of AAV-293 cell line (Stratagene) using (i) either pAAV-eGFP, pAAV-eGFP-shScramble or pAAV-eGFP-shCCK, (ii) pAAV-RC (Stratagene) containing rep and cap genes of the $\mathrm{AAV}_{2}$ and (iii) pHelper (Stratagene) encoding for the adenoviral helping functions. Following 2 days cells were collected, lysed and treated with Benzonase (50U/ml, sigma, $\left.30 \mathrm{mn}, 37^{\circ} \mathrm{C}\right)$. Viral vectors were purified by iodixanol gradient ultracentrifugation (Zolotukhin et al, 2002) followed by dialysis and 
concentration against Dulbecco PBS using centrifugal filters (Amicon Ultra-15 Centrifugal Filter Devices 50K). Viral particles were quantified by real time PCR using a plasmid standard pAAV-eGFP. To achieve comparable working concentrations, viruses were diluted in Dulbecco-PBS buffer to a final concentration of $3 \times 10^{11}$ viral genomes per $\mathrm{ml}(\mathrm{vg} / \mathrm{ml})$ and finally stored at $-80^{\circ} \mathrm{C}$ until use.

\subsection{Behavioral experiments}

2.2.1 Animals-Male C57BL/6J mice provided by Charles River (Lyon, France) were used for all the experiments. Mice were aged 8 weeks at the beginning of the experiments and housed 3-4 per cage in a 12h dark/light cycle (light from $7 \mathrm{am}$ to $7 \mathrm{pm}$ ), under controlled conditions of temperature and humidity. Food and water were available ad libitum. Experimental procedures were conducted in accordance with the European Communities Council Directive of 24 November 1986 (86/609/EEC) and approved by the local ethical committee (Comité Régional d'éthique en matière d'expérimentation animale de Strasbourg, CREMEAS, 2003-10-08-[1]-58).

2.2.2 Drugs-For surgery mice were anaesthetized using ketamine/xylazine (Virbac/ Bayer, 100/10 mg/kg). Morphine hydrochloride (Francopia), naloxone hydrochloride (a nonspecific opioid antagonist, Sigma) and anesthetics were dissolved in sterile isotonic saline $(\mathrm{NaCl} 0.9 \%)$. All the doses refer to salt weight and were administered in a volume of $10 \mathrm{ml} /$ $\mathrm{kg}$.

\subsubsection{Experimental procedure}

Experiment 1: 12 naïve mice were unilaterally injected into the BLA with either $\mathrm{AAV}_{2^{-}}$ shCCK $(\mathrm{n}=6)$ or $\mathrm{AAV}_{2}$-eGFP $(\mathrm{n}=6)$ viral vectors. To qualitatively assess their silencing activity, we performed in situ hybridization (ISH) using Dig-labeled CCK-cRNA probes. To confirm the stability of CCK knock-down over time, Dig-ISH was performed either 2 or 6 weeks following surgery ( $\mathrm{n}=3$ mice/time point/viral vector).

Experiment 2: 56 mice (2 independent cohorts) were bilaterally injected into the BLA with either $\mathrm{AAV}_{2}$-shCCK or $\mathrm{AAV}_{2}$-shScramble vectors (Cohort 1, $\mathrm{n}=16$ mice/group; Cohort 2, $\mathrm{n}=12$ mice/group) and 5 weeks later analyzed for emotional responses. Animals from the second cohort were processed only throughout tests for which an effect was observed in the first cohort. 24 hours after the last behavioral experiment, all mice were sacrificed and brains analyzed for injection accuracy and viral spread. Finally, we used Dig-ISH to qualitatively confirm the pattern of down-regulation ( $\mathrm{n}=3$ mice/condition) and $\left[{ }^{35} \mathrm{~S}\right]-\mathrm{ISH}$ to quantify the intensity of CCK knock-down in both shCCK- and shScramble-injected mice ( $\mathrm{n}=5$ mice/condition).

2.2.4 Surgery and virus delivery-Anesthetized mice were placed in a stereotaxic frame(Unimécanique, France). The skull was exposed and incisor bar adjusted such that bregma and lambda were at the same height. Stereotaxic injections were performed according to the Mouse Brain Atlas (Paxinos and Franklin, 2001). To this aim, a $5 \mu \mathrm{l}$ microsyringe (SGE Analytical Science, Australia) was mounted to a micro-drive pump (Harvard apparatus, France) and connected by a PE-10 polyethylene tubing (Harvard apparatus, France) to a stainless-steel injector needle ( $0.47 \mathrm{~mm}$ external diameter). $1.5 \mu \mathrm{l}$ of purified $\mathrm{AAV}_{2}$ viral vectors were delivered into the BLA uni- or bilaterally in experiment 1 and 2 , respectively. Injection speed was $0.1 \mu \mathrm{l} / \mathrm{min}$, and the needle was slowly withdrawn 10 min after delivery. Following surgery, mice were single housed for 48 hours to recover and then placed back in their original home cages. 
2.2.5 Behavioral testing-We evaluated the effects of local CCK knock-down in 4 categories of behaviors: anxiety-like behavior, despair-like behavior, aversive place conditioning, and withdrawal syndrome, starting 5 weeks after surgery. The design of the behavioral test battery (see Figure 1) was adapted from previous reports (Mcllwain et al, 2001, Duangdao et al, 2009) and tests were ordered from less to most stressful as follows: elevated plus-maze (EPM), open field (OF), light/dark box (LD), forced swim (FST), tail suspension tests (TS), naloxone-induced conditioned place aversion (CPA), and naloxoneprecipitated withdrawal. Elevated plus-maze was placed at the beginning of the battery as recommended by Voikar et al (2004). The inter-test intervals were selected to allow the mice to fully recover between tests. A 3-days interval was chosen between tests of the same category, a 5-days interval separate anxiety from despair behaviors, and 7-days intervals were placed before and after the naloxone-induced CPA. All behavioral tests were performed between $8 \mathrm{am}$ and $1 \mathrm{pm}$.

2.2.6 Elevated Plus-Maze-The EPM was a plus-shaped maze elevated $52 \mathrm{~cm}$ from base, with black Plexiglas floor, consisting of two open and two closed arms $(37 \times 6 \mathrm{~cm}$ each) connected by a central platform $(6 \times 6 \mathrm{~cm})$. The experiments were conducted under lowintensity light (10 lux). Movement and location of the mice were analyzed by an automated tracking system (Videotrack; View Point, Lyon, France). Each mouse was placed on the central platform facing a closed arm and observed for $5 \mathrm{~min}$. Anxiety-like behavior was assessed by measures of the time spent and number of entries in closed and open arms of the maze, and related time and activity ratios (time spent or number of entries in open arms/total time spent or number of entries in arms). Risk-taking behavior was evaluated by the percentage of time spent in the distal part of the open arms (time spent in the last $1 / 3$ of the open arm/total time in arms) and the number of head dips (total number of head dips and head dips from the distal part of the open arms). Finally, the distance traveled in the maze was used as measures of locomotor activity.

2.2.7. Open Field-The apparatus consisted of 4 equal square arenas $(50 \times 50 \mathrm{~cm})$ separated by $35 \mathrm{~cm}$-high opaque grey Plexiglas walls. Light intensity of the room was set at 50 lux. The movement and location of the mice were analyzed by an automated tracking system (Videotrack; View Point, Lyon, France). Each mouse was introduced in an arena facing a corner and recorded for 30 minutes. The following parameters were measured to assess anxiety levels: percentage of time spent in a central zone $(12 \times 12 \mathrm{~cm}$ from the outer edge) and episodes of complete immobility. Total distance traveled and number of rearing and grooming episodes were used as measures of general activity.

2.2.8. Light/Dark box-The apparatus consisted of two compartments (Panlab, Barcelona, Spain) connected through an open door located in the middle of a dividing wall. The light compartment $(25 \times 25 \times 27 \mathrm{~cm})$ consisted of white Plexiglas walls and floor, and was brightly illuminated by a white lamp (1500 lux). The dark compartment $(25 \times 16 \times 27 \mathrm{~cm})$ consisted of black Plexiglas walls and floor, and was illuminated by a red lamp ( 35 lux). Each mouse was placed in the dark compartment facing the wall opposite to the door and observed for $5 \mathrm{~min}$. Total time spent in each compartment, latency to first entry and number of entries in the light compartment were recorded as anxiety parameters.

2.2.9 Forced Swim Test-Mice were individually placed for $6 \mathrm{~min}$ in a 5-liter beaker containing 3 liters of water. Total duration of immobility, climbing and swimming episodes were scored in 2-min bins and results were expressed as percentage of total time. Latency to first immobility episode was also quoted. Each mouse was judged immobile when it ceased struggling and remained floating motionless in the water, making only the necessary movements to keep its head above water. Experimental conditions slightly differed between 
the two cohorts of experimental animals. For the first cohort, light intensity of the experimental room was set at 30 lux and temperature of water at $19^{\circ} \mathrm{C}$. For the second cohort, light intensity was set at 20 lux and temperature of water at $22^{\circ} \mathrm{C}$; moreover, the experiment was repeated on the next day.

2.2.10 Tail Suspension-This test was carried out in an automated device (MED associatesInc, St Albans, VT) consisting of 6 black boxes $(14 \times 14 \times 25 \mathrm{~cm})$. Mice were suspended $4 \mathrm{~cm}$ above the floor by an adhesive tape placed approximately $1 \mathrm{~cm}$ from the tip of the tail. Total duration of immobility was monitored during a 6-min test session. An upper and a lower threshold defined struggling (active) and immobility (passive) behaviors, respectively. The latency to the first episode of immobility was also quoted.

2.2.11 Naloxone-induced conditioned place aversion-Place conditioning experiments were performed in unbiased computerized boxes (Imetronic, Pessac, France) formed by two Plexiglas chambers $(15.5 \times 16.5 \mathrm{~cm})$ separated by a central alley $(6 \times 16.5 \mathrm{~cm})$. Compartments differed in floor texture and wall shapes. Dim light (30 lux) was used in the room to minimize levels of anxiety. On day 1, mice were allowed to freely explore the apparatus for $15 \mathrm{~min}$. The drug-paired chambers were assigned in such way that saline and naloxone groups were counterbalanced and unbiased toward contextual cues. Conditioning phase lasted 3 days. On days 2, 3 and 4 ( $8.30 \mathrm{am})$ all mice received a subcutaneous (s.c.) injection of saline and were confined to the vehicle-paired chamber for $30 \mathrm{~min}$. On the same days (4 hours later, 12:30 pm), mice received an injection of either naloxone $(1 \mathrm{mg} / \mathrm{kg} \mathrm{s.c.}$.) or saline and were confined to the drug-paired chamber for $30 \mathrm{~min}$. The testing phase was conducted on day 5. Mice were placed in the neutral central alley and allowed to explore the apparatus for $15 \mathrm{~min}$. Time spent in each chamber was recorded. Results were expressed as the percentage of time spent in the drug-paired compartment [\% time spent in the drugpaired compartment $=$ (time spent in the drug-paired compartment $) /($ time spent in both compartments) $\times 100]$.

2.2.12 Naloxone precipitated-withdrawal-shCCK and shScramble injected mice were daily injected $(8.00 \mathrm{am})$ with either morphine $(30 \mathrm{mg} / \mathrm{kg}$ i.p.) or saline during 7 days. On day 7 , all mice received a naloxone injection $(1 \mathrm{mg} / \mathrm{kg}$ s.c.) two hours after the last morphine/saline administration. Each mouse was immediately placed into a Plexiglas transparent box $(15 \times 15 \times 30 \mathrm{~cm})$ and observed individually during $20 \mathrm{~min}$ for signs of withdrawal (Matthes et al, 1996, Frenois et al., 2002). Numbers of jumps, front paw tremors, scratches, rearings, groomings, and genital lick episodes were counted. Body tremor, ptosis, mastication, and piloerection were scored 1 for appearance or 0 for nonappearance within 5 min bins. Locomotor activity over 5 min periods was rated from 0 for inactivity to 2 for high activity. A global score of withdrawal was calculated for each mouse taking into account the relative weight of each sign (adapted from Berrendero et al., 2003): (horizontal activity + rearings + scratches + genital licks + groomings $) \times 0.5+($ jumps + front paw tremors + sniffings $) \times 1+($ body tremors + ptosis + teeth chattering + piloerection $) \times 1$.

\subsection{In situ hybridization}

2.3.1 CCK-cRNA probes preparation-DNA template for CCK cRNA-probes (258-600,343bp) was generated by RT-PCR (Sigma, forward primer: $5^{\prime}$ CTGTACCCAAGCTTGATACATCCAGCAGGTCCGCAAA- $3^{\prime}$, reverse primer:5' TTTCCTTGGGAATTCAGGAAACACTGCCTTCCGACCAC- $3^{\prime}$ ) using total mouse brain RNA extracted by TRIzol reagent (Invitrogen, Cergy Pontoise, France) according to the manufacturer's instructions. The template was cloned into pcDNA3 (Invitrogen) and verified by sequencing. Sequence probe alignment was confirmed with BLASTN 2.2.18 software (http://blast.ncbi.nlm.nih.gov, NCBI). Next, CCK-cDNA plasmid $(20 \mu \mathrm{g})$ was 
linearized by enzymatic digestion of EcoRI for sense probe and HindIII for anti-sense probe, and linearized DNA $(1 \mu \mathrm{g})$ was transcribed using T7 or Sp6 RNA polymerases (Promega) for sense and anti-sense probes production respectively. For Dig-labeled probes, DIG RNA labeling mix 1X(Roche) was used according to manufacturer's specifications. Quality of the RNA was evaluated by agarose gel electrophoresis (RiboRuler Low Range RNA ladder, Fermentas) and concentration determined by spectrophotometry (Nanodrop Labtech ND-1000). For radiolabeled-probes, CTP- a ${ }^{35}$ radionuclides (PerKinElmer) were added to the synthetizing mix. $\mathrm{S}^{35}$-probes were purified by gravity-flow chromatography on illustra NICK Columns (GE Healthcare) and specific activity was measured using a topcount apparatus(Packard).

2.3.2 Tissue preparation-Mice were sacrificed by cervical dislocation, brains were rapidly removed, frozen in OCT (Optimal Cutting Temperature medium, Thermo Scientific) and stored at $-80^{\circ} \mathrm{C}$ until use. Coronal brain sections $(20 \mu \mathrm{m})$ were obtained for BLA ( -0.8 to $-1.8 \mathrm{~mm}$ from bregma) according to the mouse brain atlas (Paxinos and Franklin, 2001) using a cryostat microtome (Leica CM3500) at $-20^{\circ} \mathrm{C}$. Slides were mounted onto Superfrost slides (Thermo Scientific) and immediately fixed at room temperature (RT) for 15 min with $4 \%$ paraformaldehyde (PFA), 0.1M phosphate buffer (PB, pH 7.4). Fixed sections were then washed in $0.1 \mathrm{M} \mathrm{PB}$ for $15 \mathrm{~min}$, air-dried and stored at $-80^{\circ} \mathrm{C}$ until use.

2.3.3 In situ hybridization (ISH)—Dig- and $\left.{ }^{35} \mathrm{~S}\right]$-labeled RNA probes were used for ISH, following the methods previously described by Chotteau-Lelievre et al (2006). Briefly, fixed brain sections kept at $-80^{\circ} \mathrm{C}$ were thawed at RT for $30 \mathrm{~min}$ and rehydrated in $1 \times \mathrm{PBS}$ for $10 \mathrm{~min}$. Sections were then incubated at $65^{\circ} \mathrm{C}$ for $16 \mathrm{~h}$ in a hybridization mix [formamide $50 \%$ (molecular biology grade, Sigma-Aldrich); dextran sulfate 10\%; Denhardt's 1x; tRNA $1 \mathrm{mg} / \mathrm{ml}$ (from Baker's yeast, Sigma-Aldrich); $\mathrm{NaCl} 300 \mathrm{mM}$; Tris-HCl 20mM pH 6.8; EDTA 5mM; $\mathrm{NaH}_{2} \mathrm{PO}_{4} 5.4 \mathrm{mM} ; \mathrm{Na}_{2} \mathrm{HPO}_{4} 4.6 \mathrm{mM}$; plus $10 \mathrm{mM}$ DTT for radioactive ISH] with either Dig- or $\mathrm{S}^{35}$-labeled RNA probes at the concentrations of $1.5 \mathrm{ng} / \mu 1$ or 20,000 $\mathrm{cpm} / \mu \mathrm{l}$, respectively. DIG-labeled brain sections were afterward incubated with an alkaline phosphatase-labeled anti-DIG antibody (1:1500, Roche) in blocking solution [2\% Roche blocking; $20 \%$ heat inactivated goat serum, MABT 1×]. Staining was performed with Nitroblue tetrazolium and bromo-chloro-indolyphosphate (NBT/BCIP) as color substrates by incubating the slides in staining solution [polyvinyl alcohol $0.5 \%$ (Sigma-aldrich); $\mathrm{NaCl}$ $100 \mathrm{mM}$; Tris- $\mathrm{HCl} 100 \mathrm{mM} \mathrm{pH} \mathrm{9.5;} \mathrm{MgCl}_{2} 50 \mathrm{mM}$; Tween20 0.1\%; NBT 0.35\% (Roche); BCIP $0.35 \%$ (Roche)] at RT under light-protected conditions until the signal becomes visible (12h). Next, slides were washed $2 \times 10 \mathrm{~min}$ (PBS 1×, 1mM EDTA), air-dried and mounted with Eukitt (VWR). To generate autoradiograms, $\left[{ }^{35} \mathrm{~S}\right]$-labeled brain sections were exposed to Kodak Biomax MR films (Sigma-Aldrich) at $-80^{\circ} \mathrm{C}$ for seven days, simultaneously with a $\left[{ }^{14} \mathrm{C}\right]$ standard (ARC 0146; American Radiolabeled Chemicals). Films were developed with a Kodak MIN-R Processor (Carestream Health).

2.3.4 Image analysis-Brain sections were observed under epifluorescent microscopy (Leica) and autoradiograms under a macroscope and bright lighting. In both cases, images were acquired with a CCD camera (CoolSNAP, Roper Scientific). For autoradiograms, 10 brain sections of each mouse were individually captured as high resolution (600 dpi) 8-bit images. In each section, ImageJ was used to bilaterally draw regions of interest (ROI) and measure mean grey levels in (i) the BLA, where the GFP signal was previously detected, (ii) the striatum, a region lacking CCK mRNA (Schiffmann and Vanderhaeghen, 1991, Meziane et al, 1997) and (iii) the retrosplenial agranular cortex (RSA). Grey level values were then transformed into relative radioactive counts by calibration with the co-exposed $\left[{ }^{14} \mathrm{C}\right]$ standard using a Rodbard non-linear regression curve. As recommended by AmbesiImpiombato et al (2003), radioactive value in the striatum, corresponding to non specific 
hybridization, was subtracted to both BLA and RSA. As CCK mRNA expression level in RSA was not affected by viral vector injections in the BLA (shScramble group: $92.1 \pm 11.8$ $\mathrm{nCi} / \mathrm{g}$; shCCK group: $94.2 \pm 8.7 \mathrm{nCi} / \mathrm{g}$ ), normalized BLA radioactive values were calculated by dividing BLA value by that in the RSA of the same section.

\subsection{Statistical analysis}

Statistical analysis were performed with Statistica software v8 (www.statsoft.com) and Graph-Pad Prism software v5 (www.graphpad.com). All data are expressed as mean group value \pm S.E.M. and statistical significance was defined as $p<0.05$. Unpaired Student's t-test (two-tailed) was used to compare $\mathrm{AAV}_{2}$-shCCK vs. $\mathrm{AAV}_{2}$-shScramble injected mice in autoradiographic film quantification. As regards to behavioral experiments, a two-way ANOVA was used for EPM with Cohort and shRNA as between-group factors, and time spent in and number of entries to the open and closed arms as within-group factors. A oneway ANOVA was used in the FST for Cohort 1 to compare immobility and latency time between injected mice, and a two-way ANOVA with repeated measures for bin comparisons. In cohort 2, a two-way ANOVA with repeated measures was used with shRNA as between-group factor and days/bins as within-group factor. For both cohorts, significant main effects were followed by post-hoc test (Newman Keuls). Place conditioning data were analyzed using a three-way ANOVA with Cohort, shRNA and treatment as between-group factors and session (pre- VS. post-conditioning) as within-group factor. Data from the scoring of somatic signs of withdrawal were analyzed using two-way ANOVAs with treatment and shRNA as group factors. One-way ANOVA were also used to analyze the data from the open field, light/dark box and tail suspension tests. Extreme studentized deviate (ESD) method was used to determine significant $(\mathrm{p}<0.05)$ outliers. 2 mice/group were excluded in cohort 1 during the forced swim test.

\section{Results}

\subsection{CCK down-regulation in the BLA in vivo}

In experiment 1 we evaluated the efficacy of $\mathrm{AAV}_{2}$-shCCK viral vector in vivo. Animals were injected unilaterally in the BLA with either $\mathrm{AAV}_{2}$-shCCK or control $\mathrm{AAV}_{2}$-eGFP vectors (see Methods). Two or 6 weeks following surgery, brain sections at the level of the BLA were analyzed for cellular integrity, eGFP fluorescence and CCK mRNA expression. Representative images are shown in Figure 2. For all animals, we found intact DAPI staining and a strong expression of eGFP, confirming the absence of toxicity due to surgery or viral infection and robust transgene expression, respectively. Using $\mathrm{AAV}_{2}$-eGFP (Figure 2 , top panels), CCK mRNA levels were comparable between injected and contra-lateral noninjected BLAs (data not shown), indicating that surgery and viral infection have no nonspecific effect on CCK expression. On the contrary, 2 or 6 weeks after the surgery, the mcck transcript was strongly decreased in $\mathrm{AAV}_{2}$-shCCK treated mice at the site of injection (Figure 2, bottom panels). CCK down-regulation perfectly overlapped the viral spread after 2 and 6 weeks, as revealed by eGFP detection, demonstrating efficacy and stability of shRNA-induced CCK down-regulation in the BLA. The extent of down-regulation was quantified in a further experiment (experiment 2), after behavioral testing (see below).

\subsection{Behavioral effects of CCK down-regulation in the BLA}

In experiment 2 we prepared two cohorts of animals injected bilaterally with either $\mathrm{AAV}_{2^{-}}$ shCCK or $\mathrm{AAV}_{2}$-shScramble (see Methods) and examined emotional responses in either an extended (cohort 1) or more limited (cohort 2) test series (see Figure 1).

Anxiety like-behavior-We first examined whether CCK mRNA down-regulation in BLA influences levels of anxiety. In the EPM, data from the two cohorts showed no 
statistical difference and were pooled (Figure 3). $\mathrm{AAV}_{2}$-shCCK injected mice spent more time (Cohort: $\mathrm{F}_{(1,40)}=3.92$, NS; shRNA: $\mathrm{F}_{(1,40)}=1.89$, NS; arms: $\mathrm{F}_{(1,40)}=25.19$, $\mathrm{p}<0.001$; shRNA $\times$ arms interaction $\left.\mathrm{F}_{(1,40)}=8.44, \mathrm{p}<0.01\right)$ and entered more often in open arms (Cohort: $\mathrm{F}_{(1,40)}=3.58$, NS; shRNA: $\mathrm{F}_{(1,40)}=0.93$, NS; arms: $\mathrm{F}_{(1,40)}=24.04$, $\mathrm{p}<0.001$; shRNA $\times$ arms interaction $\left.F_{(1,40)}=19.04, p<0.001\right)$ as compared to $\mathrm{AAV}_{2}$-shScramble injected controls (Figure $3 \mathrm{~A}$ ). This indicates that $\mathrm{AAV}_{2}$-shCCK treatment resulted in decreased anxiety-like behavior. Accordingly, time (Cohort: $\mathrm{F}_{(1,40)}=0.69$, NS; $\operatorname{shRNA} \mathrm{F}_{(1,40)}=8.50$, $\mathrm{p}<0.01)$ and entry (Cohort: $\mathrm{F}_{(1,40)}=3.99$, NS; shRNA: $\mathrm{F}_{(1,40)}=16.63$, $\left.\mathrm{p}<0.001\right)$ ratios were increased in $\mathrm{AAV}_{2}$-shCCK injected mice (Figure 3A). Total distance traveled in the maze was similar between groups (Cohort: $\mathrm{F}_{(1,40)}=3.03$, NS; shRNA: $\mathrm{F}_{(1,40)}=0.11$, NS), suggesting that CCK knock-down had no effect on locomotor activity (Figure 3A).

$\mathrm{AAV}_{2}$-shCCK injected mice also showed increased risk-taking behavior, as illustratedin Figure 3B. These mice displayed increased total number of head-dips $\left(\right.$ Cohort: $\mathrm{F}_{(1,40)}=0.075$, NS; shRNA: $\left.\mathrm{F}_{(1,40)}=7.39, \mathrm{p}<0.01\right)$, increased number of head-dips from thedistal part of the open arms (Cohort: $F_{(1,40)}=2.67$, NS; shRNA: $F_{(1,40)}=9.47$, p<0.01) andincreased time spent in the distal part of the open arms (Cohort: $\mathrm{F}_{(1,40)}=0.51$, NS; $\operatorname{shRNA}: \mathrm{F}_{(1,40)}=5.40, \mathrm{p}<0.05$ ) compared to $\mathrm{AAV}_{2}$-shScramble.

Animals from Cohort 1 were further tested for anxiety-like behavior in the open fieldand the light/dark box. No significant difference between $\mathrm{AAV}_{2}$-shCCK and $\mathrm{AAV}_{2}$-shScramble groups was found in these tests (Table 1).

Despair-like behavior-We next analyzed the effects of CCK mRNA down-regulation in BLA on despair behavior in the forced swim test. In the first animal cohort (Figure 4A), $\mathrm{AAV}_{2}$-shCCK injected mice showed less immobility time as compared to $\mathrm{AAV}_{2^{-}}$ shScramble injected mice $\left(\mathrm{F}_{(1,19)}=17.87, \mathrm{p}<0.001\right)$, suggesting a reduction in despair-like behavior. When split into 2-min time bins, differences in immobility time appeared significant during the last two bins (shRNA: $\mathrm{F}_{(1,19)}=17.87$, $\mathrm{p}<0.001$; Bins: $\mathrm{F}_{(2,38)}=81.52$, $\mathrm{p}<0.001$; Newman Keuls: Bin 1, NS; Bin 2, $\mathrm{p}<0.01$; Bin 3, $\mathrm{p}<0.05)$. No significant difference between groups was detected for latency to the first immobility episode $\left(\mathrm{F}_{(1,19)}=0.68, \mathrm{NS}\right)$.

In the second animal cohort, tested under less stressful conditions (Figure 4B), repeated measure ANOVA revealed a significant decrease of total immobility in $\mathrm{AAV}_{2}$-shCCKtreated mice as compared to $\mathrm{AAV}_{2}$-shScramble-treated animals on the second day of testing, and a significant effect of test repetition only in $\mathrm{AAV}_{2}$-shScramble injected mice (shRNA: $\mathrm{F}_{(1,17)}=9.68, \mathrm{p}<0.01$; Days: $\mathrm{F}_{(1,17)}=17.98, \mathrm{p}<0.001$; Newman Keuls: shScramble day1 vs. day2, p<0.01; shCCK day1 vs. day2, NS; day 1 shScramble $v s$. shCCK, NS; day 2 shScramble vs. shCCK, p $<0.001$ ). When split into 2-min time bins, differences in immobility time also appeared significant on the second day of testing (day 1 shRNA: $F_{(1,17)}=3.75$, NS; bins: $F_{(2,34)}=90.66$, $p<0.001$; day 2 shRNA: $F_{(1,17)}=11.34, p<0.01$; bins: $\left.\mathrm{F}_{(2,34)}=16.07, \mathrm{p}<0.001\right)$. Latency to the first immobility episode was increased in shCCKinjected mice on day 1 (shRNA: $\mathrm{F}_{(1,17)}=4.54$, $\mathrm{p}<0.05$; Days: $\mathrm{F}_{(1,17)}=121.76, \mathrm{p}<0.001$; Newman Keuls: shScramble day1 vs. day2, $\mathrm{p}<0.001$; shCCK day1 vs. day2, $\mathrm{p}<0.001$; Day 1 shScramble vs. shCCK, p $<0.05$; Day 2 shScramble vs. shCCK, NS). Altogether, these results suggest that down-regulating CCK expression in the amygdala decreases despair-like behavior.

Animals from Cohort 1 were further tested in the tail suspension paradigm No statistical difference was detected for any behavioral parameter in this test (Table 1). 
Aversive place conditioning-We evaluated the ability of $\mathrm{AAV}_{2}$-shCCK injected mice to acquire conditioned place aversion (CPA) to naloxone. Statistical analysis showed no significant effect of cohort (cohort: $\mathrm{F}_{(1,36)} 0.39$, NS) and data from the two cohorts were pooled (Figure 5). ANOVA revealed a significant effect of naloxone treatment and conditioning sessions (treatment: $\mathrm{F}_{(1,36)}=7.20$, $\mathrm{p}<0.01$; session $\mathrm{F}_{(1,36)}=11.57$, $\mathrm{p}<0.001$; session $\times$ treatment interaction $\left.\mathrm{F}_{(1,36)}=9.08, \mathrm{p}<0.01\right)$, indicating that naloxone produced conditioned place aversion under our experimental conditions. There was no effect of $\mathrm{AAV}_{2}$-shCCK injections (shRNA: $\mathrm{F}_{(1,36)}=1.45, \mathrm{NS}$ ) and no interaction with naloxone treatment $\left(\operatorname{shRNA} \times\right.$ treatment interaction $\left.\mathrm{fF}_{(1,36)}=0.05, \mathrm{NS}\right)$. Post-hoc analysis indicated that the $\mathrm{AAV}_{2}$-shScramble naloxone-treated post-conditioning group was significantly different from both $\mathrm{AAV}_{2}$-shScramble naloxone-treated pre-conditioning group $(\mathrm{p}<0.001)$ and $\mathrm{AAV}_{2}$-shScramble saline-treated post-conditioning group $(\mathrm{p}<0.01)$. On the contrary, the $\mathrm{AAV}_{2}$-shCCK naloxone-treated post-conditioning group were neither different from $\mathrm{AAV}_{2} \mathrm{C}^{-}$ shCCK naloxone-treated pre-conditioning $(\mathrm{p}>0.05)$ nor $\mathrm{AAV}_{2}$-shCCK saline-treated postconditioning ( $p>0.05$ ) groups, suggesting that $\mathrm{AAV}_{2}$-shCCK mice did not show a strong aversion to the naloxone-paired compartment and that CCK down-regulation in the BLA reduces aversive place conditioning.

Physical dependence to morphine-Finally, we examined the effects of CCK downregulation on somatic signs of morphine-precipitated withdrawal. A significant morphine withdrawal syndrome was observed after naloxone administration in both $\mathrm{AAV}_{2}$-shCCK and $\mathrm{AAV}_{2}$-shScramble injected mice (horizontal activity: shRNA $\mathrm{F}_{(1,12)}=0.00$, NS; treatment $\mathrm{F}_{(1,12)}=8.54, \mathrm{p}<0.01$; rearing: $\operatorname{shRNA} \mathrm{F}_{(1,12)}=2.18$, NS; treatment $\mathrm{F}_{(1,12)}=30.93$, p $<0.001$; jumping: shRNA $\mathrm{F}_{(1,12)}=1.17$, NS; treatment $\mathrm{F}_{(1,12)}=26.34$, $\mathrm{p}<0.001$; front paw tremors: shRNA $\mathrm{F}_{(1,12)}=1.40$, NS; treatment $\mathrm{F}_{(1,12)}=42.46$, $\mathrm{p}<0.001$; scratches: shRNA $\mathrm{F}_{(1,12)}=0.04$, NS; treatment $\mathrm{F}_{(1,12)}=12.94$, $\mathrm{p}<0.01$; genital licks: shRNA $\mathrm{F}_{(1,12)}=0.45$, NS; treatment $\mathrm{F}_{(1,12)}=2.17$, NS; grooming: shRNA $\mathrm{F}_{(1,12)}=0.08$, NS; treatment $\mathrm{F}_{(1,12)}=13.25$, $\mathrm{p}<0.01$; body tremor: $\operatorname{shRNA} \mathrm{F}_{(1,12)}=0.33$, NS; treatment $\mathrm{F}_{(1,12)}=8.33$, $\mathrm{p}<0.01$; ptosis: shRNA $\mathrm{F}_{(1,12)}=0.20$, NS; treatment $\mathrm{F}_{(1,12)}=88.20, \mathrm{p}<0.001$; mastication: shRNA $\mathrm{F}_{(1,12)}=0.00$, NS; treatment $\mathrm{F}_{(1,12)}=338.00$, $\mathrm{p}<0.001$; piloerection: $\operatorname{shRNA} \mathrm{F}_{(1,12)}=0.00$, NS; treatment $\mathrm{F}_{(1,12)}=450.00, \mathrm{p}<0.001$ ) (see Table 2). Two-way ANOVA analysis of global withdrawal score (Figure 6) showed a significant effect of treatment $\left(\mathrm{F}_{(1,12)}=10.10\right.$, $\mathrm{p}<0.001)$ but no effect of shRNA injection $\left(\mathrm{F}_{(1,12)}=0.17, \mathrm{NS}\right)$. Thus the viral treatment had no effect on somatic signs of morphine withdrawal.

\subsection{Accuracy and efficiency of CCK down-regulation in the BLA in behaviorally tested animals}

In experiment 2, after the last behavioral experiment, we examined accuracy of viral injections in the BLA (Figure 7). Most animals showed viral expression in the BLA and animals showing absent or misplaced eGFP expression were excluded from statistical analysis (Cohort 1: 7 mice; Cohort 2: 5 mice, Figure 7A). Qualitative ISH confirmed CCK down-regulation (Figure 7B). Quantification was performed using $\left[{ }^{35} \mathrm{~S}\right]-\mathrm{ISH}$ and showed a significant 35\% reduction of CCK mRNA probe binding in the BLA (Unpaired Student's ttest, $\mathrm{t}=3.17, \mathrm{p}<0.01)$ of $\mathrm{AAV}_{2}$-shCCK injected mice, as compared to controls $\left(\mathrm{AAV}_{2^{-}}\right.$ shScramble) (Figure 7C). Together with experiment 1, therefore, these results confirm efficient -although partial- down-regulation of CCK expression in the BLA throughout the behavioral analysis.

\section{Discussion}

The aim of the present study was to examine the role of CCK expressed at the level of the basolateral nucleus of the amygdala in negative emotional responses. We used a local 
shRNA approach to evaluate the implication of amygdalar CCK in several behavioral responses, including anxiety and despair-like behaviors, aversive place conditioning and morphine withdrawal syndrome.

CCK has been largely implicated in anxiety-related behaviors as demonstrated in human studies (Berna et al., 2007, Eser et al, 2011), as well as in animal models using either pharmacological (Rotzinger et al., 2010, Wang et al, 2011) or genetic approaches (Dauge et al, 2001, Raud et al., 2005, Chen et al., 2010). Our data from the EPM experiments showed a significant enhancement of exploration in the open arms and increased risk-taking behavior in two independent cohorts of mice with down-regulated amygdalar CCK. The observed effects are not attributable to general activity changes, because shRNA treatment produced no change in total locomotor activity in this test. Our results therefore show that CCK down-regulation decreases levels of anxiety, in agreement with the well-established anxiogenic role of CCK in previous reports. Notably, we found no effect of the CCK knockdown in two other behavioral models of anxiety, the open field and the light/dark box. This could be due to handling and test history effects, as previously reported by Voikar et al (2004), or to qualitative and quantitative differences across the three anxiety tests (Cryan and Holmes, 2005). All three models are primarily based on free exploration of novel environments, but involve different stressful stimuli (Ramos, 2008), therefore similar levels of anxiety may express differently across these tests (van Gaalen and Steckler, 2000). Further, distinct genes () and brain networks (Turri, 2001) and brain networks (Menard and Treit, 1999) contribute to the behavioral responses across tests, and amygdala may be a stronger contributor to behaviors in the EPM under our experimental conditions. Finally, the EPM generally represents a more stressful situation for mice (Holmes et al, 2003) compared to the open field or light/dark box, which may be a more favorable situation to reveal decreased anxiety in mice with down regulated CCK.

The observation that local CCK down-regulation, specifically at the level of BLA, strongly modifies behavioral parameters in the EPM reveals a main role for amygdalar CCK in the regulation of anxiety. This is consistent with the notion that high CCK activity in the amygdala is associated with high levels of anxiety. Sherrin et al (2009) demonstrated that both CCK mRNA expression levels and $\mathrm{CCK}_{2}-\mathrm{R}$ immunoreactivity were elevated in BLA of mice presenting anxiogenic responses in the open field and EPM test, both elicited by pretreatment with an agonist for corticotrophin-releasing factor receptor 1. Also, studies in rats showed that local activation of amygdalar $\mathrm{CCK}_{2}-\mathrm{R}$ reduced time spent in open arms of the plus-maze (Belcheva et al, 1994) and potentiated the startle response in the acoustic startle test (Frankland et al., 1997). These studies together with our data suggest that CCK acting at local $\mathrm{CCK}_{2}-\mathrm{R}$ receptors of the BLA increases levels of anxiety. This mechanism is in accordance with anatomical and electrophysiological studies indicating that $\mathrm{CCK}$ and $\mathrm{CCK}_{2}-\mathrm{R}$ are mainly expressed in GABAergic interneurons of the BLA (Chung and Moore, 2009, Jasnow et al., 2009). Altogether therefore, the data suggest that a large part of anxiogenic activity of the CCK system operates via local mechanisms within the BLA, likely at the level of GABAergic interneurons. We cannot exclude, however, that CCK possibly expressed at thelevel of glutamatergic neurons in the BLA (Mascagni and McDonald, 2003) and acting atreceptors in BLA projections areas may also be involved, and this will be investigated in future studies. In addition, CCK expressed in cortical afferent neurons to the BLA may alsocontribute to regulate anxiety-like behaviors upstream the BLA within the cortico-amygdala circuitry.

The CCK system was also involved in depressive-related behaviors, although this aspect of CCK function is less-well documented. Polymorphisms of the CCK gene were associated with susceptibility for suicidal behavior (Shindo and Yoshioka, 2005, Berna et al, 2007). In preclinical studies, systemic administration of $\mathrm{CCK}_{2}-\mathrm{R}$ antagonists decreased immobility in 
the forced swim test after chronic social defeat (Becker et al, 2008), with synergistic effects of the enkephalinase inhibitor RB101 (Hernando et al., 1996). In agreement with these previous reports, our data show a reduction of despair-like behavior upon $\mathrm{AAV}_{2}$-shCCK treatment in the forced swim test. The antidepressant-like effect of CCK down-regulation was not detected in the tail suspension test. The two tests share common predictive validity (Kulkarni and Dhir, 2007) but show different sensitivities in response to experimental manipulations and environmental factors (Miller et al, 2010) and engage different neurochemical substrates (Renard et al, 2003), particularly in C57B16/J mice used in the present study (Mineur et al, 2006, Goeldner et al., 2011). Importantly, our finding that local CCK down-regulation specifically in the BLA reduces despair behavior in the forced swim test demonstrates for the first time a key role for amygdalar CCK in depressive-like responses. As for anxiety-related behaviors, the modulation of depressive states by CCK expressed at the level of the BLA may recruit local mechanisms, which requires further investigation.

Finally CCK was also involved in aversive responses (Valverde and Roques, 1998, Mitchell et al, 2006) and we evaluated the effect of local CCK mRNA down-regulation in two aversive situations, i.e. place aversion induced by naloxone and the physical consequences of morphine withdrawal. $\mathrm{AAV}_{2}$-shCCK injected mice showed a trend toward reduced place aversion in the naloxone-induced CPA paradigm, suggesting that CCK either contributes to aversive properties of naloxone or participates in place learning (LejMerrer et al, 2011), at least partially. Further investigations will be necessary to clarify whether decreased naloxone-CPA may reflect a role of amygdalar CCK in cognition or hedonic homeostasis. We otherwise found no effect of amygdalar CCK down-regulation in somatic signs of morphine withdrawal, although naloxone-precipitated withdrawal was increased in $\mathrm{CCK}_{2}-\mathrm{R}$ KO mice (Pommier et al, 2002). It is likely that local CCK in the amygdala does not substantially contribute to the physical withdrawal syndrome, which engages many transmitter systems throughout the brain (Koob and Volkow, 2010).

In conclusion, this study establishes that CCK produced at the level of amygdala increases levels of anxiety and favors despair behavior, possibly via local activity. This neural mechanism may contributes to mood homeostasis in humans, and be a causal factor in panic disorder and depression.

\section{Acknowledgments}

We would like to thank Gilles Duval and Dzemailj Memedov for animal care, as well as Pascal Kessler, Muriel Koch and Didier Hentsch for help in image acquisition, analysis and quantification. This work was supported by the Centre National de la Recherche Scientifique, Institut National de la Santé et de la Recherche Médicale, and Université de Strasbourg. We thank the European Union (GENADDICT/FP6 005166), and the National Institutes of Health (NIAAA AA-16658 and NIDA DA-16768), for financial support.

\section{References}

Ambesi-Impiombato A, D'Urso G, Muscettola G, de Bartolomeis A. Method for quantitative in situ hybridization histochemistry and image analysis applied for Homer1a gene expression in rat brain. Brain Res Brain Res Protoc. 2003; 11:189-196. [PubMed: 12842224]

Becker C, Zeau B, Rivat C, Blugeot A, Hamon M, Benoliel JJ. Repeated social defeat-induced depression-like behavioral and biological alterations in rats: involvement of cholecystokinin. Mol Psychiatry. 2008; 13:1079-1092. [PubMed: 17893702]

Beinfeld MC. An introduction to neuronal cholecystokinin. Peptides. 2001; 22:1197-1200. [PubMed: 11457511] 
Belcheva I, Belcheva S, Petkov VV, Petkov VD. Asymmetry in behavioral responses to cholecystokinin microinjected into rat nucleus accumbens and amygdala. Neuropharmacology. 1994; 33:995-1002. [PubMed: 7845556]

Berna MJ, Tapia JA, Sancho V, Jensen RT. Progress in developing cholecystokinin(CCK)/gastrin receptor ligands that have therapeutic potential. Curr Opin Pharmacol. 2007; 7:583-592. [PubMed: 17997137]

Bradwejn J, Koszycki D. Cholecystokinin and panic disorder: past and future clinical research strategies. Scand J Clin Lab Invest Suppl. 2001; 234:19-27. [PubMed: 11713976]

Cain BM, Connolly K, Blum A, Vishnuvardhan D, Marchand JE, Beinfeld MC. Distribution and colocalization of cholecystokinin with the prohormone convertase enzymes PC1, PC2, and PC5 in rat brain. J Comp Neurol. 2003; 467:307-325. [PubMed: 14608596]

Chen Q, Tang M, Mamiya T, Im HI, Xiong X, Joseph A, Tang YP. Bi-directional effect of cholecystokinin receptor-2 overexpression on stress-triggered fear memory and anxiety in the mouse. PLoS One. 2010; 5:e15999. [PubMed: 21209861]

Chotteau-Lelievre A, Dolle P, Gofflot F. Expression analysis of murine genes using in situ hybridization with radioactive and nonradioactively labeled RNA probes. Methods Mol Biol. 2006; 326:61-87. [PubMed: 16780194]

Chung L, Moore SD. Cholecystokinin excites interneurons in rat basolateral amygdala. Neurophysiol. 2009; 102:272-284.

Cryan JF, Holmes A. The ascent of mouse: advances in modelling human depression and anxiety. Nat Rev Drug Discov. 2005; 4:775-790. [PubMed: 16138108]

Dauge V, Sebret A, Beslot F, Matsui T, Roques BP. Behavioral profile of CCK2 receptor- deficient mice. Neuropsychopharmacology. 2001; 25:690-698. [PubMed: 11682252]

Duangdao DM, Clark SD, Okamura N, Reinscheid RK. Behavioral phenotyping of neuropeptide S receptor knockout mice. Behav Brain Res. 2009; 205:1-9. [PubMed: 19646487]

Eser D, Uhr M, Leicht G, Asmus M, Langer A, Schule C, Baghai TC, Mulert C, Rupprecht R. Glyoxalase-I mRNA expression and CCK-4 induced panic attacks. J Psychiatr Res. 2011; 45:6063. [PubMed: 20542521]

Frankland PW, Josselyn SA, Bradwejn J, Vaccarino FJ, Yeomans JS. Activation of amygdale cholecystokininB receptors potentiates the acoustic startle response in the rat. Neurosci. 1997; 17:1838-1847.

Frenois F, Cador M, Caille S, Stinus L, Le Moine C. Neural correlates of the motivational and somatic components of naloxone-precipitated morphine withdrawal. Eur J Neurosci. 2002; 16:1377-1389. [PubMed: 12405997]

Frenois F, Stinus L, Di Blasi F, Cador M, Le Moine C. A specific limbic circuit underlies opiate withdrawal memories. J Neurosci. 2005; 25:1366-1374. [PubMed: 15703390]

Goeldner C, Lutz PE, Darcq E, Halter T, Clesse D, Ouagazzal AM, Kieffer BL. Impaired emotionallike behavior and serotonergic function during protracted abstinence from chronic morphine. Biol Psychiatry. 2011; 69:236-244. [PubMed: 20947067]

Hebb AL, Poulin JF, Roach SP, Zacharko RM, Drolet G. Cholecystokinin and endogenous opioid peptides: interactive influence on pain, cognition, and emotion. Prog Neuropsychopharmacol Biol Psychiatry. 2005; 29:1225-1238. [PubMed: 16242828]

Hernando F, Fuentes JA, Fournie-Zaluski MC, Roques BP, Ruiz-Gayo M. Antidepressant- like effects of CCK(B) receptor antagonists: involvement of the opioid system. Eur J Pharmacol. 1996; 318:221-229. [PubMed: 9016909]

Holmes A, Kinney JW, Wrenn CC, Li Q, Yang RJ, Ma L, Vishwanath J, Saavedra MC, Innerfield CE, Jacoby AS, Shine J, Iismaa TP, Crawley JN. Galanin GAL-R1 Receptor Null Mutant Mice Display Increased Anxiety-Like Behavior Specific to the Elevated Plus-Maze. Neuropsychopharmacology. 2003; 28:1031-1044. [PubMed: 12700679]

Jasnow AM, Ressler KJ, Hammack SE, Chhatwal JP, Rainnie DG. Distinct subtypes of cholecystokinin (CCK)-containing interneurons of the basolateral amygdala identified using a CCK promoter-specific lentivirus. J Neurophysiol. 2009; 101:1494-1506. [PubMed: 19164102]

Koob GF, Volkow ND. Neurocircuitry of addiction. Neuropsychopharmacology. 2010; 35:217-238. [PubMed: 19710631] 
Kulkarni SK, Dhir A. Effect of various classes of antidepressants in behavioral paradigms of despair. Prog Neuropsychopharmacol Biol Psychiatry. 2007; 31:1248-1254. [PubMed: 17570574]

Le Merrer J, Plaza-Zabala A, Del Boca C, Matifas A, Maldonado R, Kieffer BL. Deletion of the delta Opioid Receptor Gene Impairs Place Conditioning But Preserves Morphine Reinforcement. Biol Psychiatry. 2011; 69:700-703. [PubMed: 21168121]

LeDoux JE. Emotion circuits in the brain. Annu Rev Neurosci. 2000; 23:155-184. [PubMed: 10845062]

Lu L, Zhang B, Liu Z, Zhang Z. Reactivation of cocaine conditioned place preference induced by stress is reversed by cholecystokinin-B receptors antagonist in rats. Brain Res. 2002; 954:132-140. [PubMed: 12393241]

Mascagni F, McDonald AJ. Immunohistochemical characterization of cholecystokinin containing neurons in the rat basolateral amygdala. Brain Res. 2003; 976:171-184. [PubMed: 12763251]

Matthes HW, Maldonado R, Simonin F, Valverde O, Slowe S, Kitchen I, Befort K, Dierich A, Le Meur M, Dolle P, Tzavara E, Hanoune J, Roques BP, Kieffer BL. Loss of morphine-induced analgesia, reward effect and withdrawal symptoms in mice lacking the mu-opioid-receptor gene. Nature. 1996; 383:819-823. [PubMed: 8893006]

McIlwain KL, Merriweather MY, Yuva-Paylor LA, Paylor R. The use of behavioral test batteries: effects of training history. Physiol Behav. 2001; 73:705-717. [PubMed: 11566205]

Menard J, Treit D. Effects of centrally administered anxiolytic compounds in animal models of anxiety. Neurosci Biobehav Rev. 1999; 23(4):591-613. [PubMed: 10073896]

Meziane H, Devigne C, Tramu G, Soumireu-Mourat B. Distribution of cholecystokinin immunoreactivity in the BALB/c mouse forebrain: an immunocytochemical study. J Chem Neuroanat. 1997; 12:191-209. [PubMed: 9141651]

Miller BH, Schultz LE, Gulati A, Su AI, Pletcher MT. Phenotypic characterization of a genetically diverse panel of mice for behavioral despair and anxiety. PLoS One. 2010; 5:e14458. [PubMed: 21206921]

Mineur YS, Belzung C, Crusio WE. Effects of unpredictable chronic mild stress on anxiety and depression-like behavior in mice. Behav Brain Res. 2006; 175:43-50. [PubMed: 17023061]

Mitchell JM, Bergren LJ, Chen KS, Fields HL. Cholecystokinin is necessary for the expression of morphine conditioned place preference. Pharmacol Biochem Behav. 2006; 85:787-795. [PubMed: 17196636]

Mutt V, Jorpes JE. Structure of porcine cholecystokinin-pancreozymin. 1. Cleavage with thrombin and with trypsin. Eur J Biochem. 1968; 6:156-162. [PubMed: 5725809]

Noble F, Roques BP. Phenotypes of mice with invalidation of cholecystokinin (CCK(1) or WCCK(2)) receptors. Neuropeptides. 2002; 36:157-170. [PubMed: 12359506]

Noble F, Wank SA, Crawley JN, Bradwejn J, Seroogy KB, Hamon M, Roques BP. International Union of Pharmacology. XXI. Structure, distribution, and functions of cholecystokinin receptors. Pharmacol Rev. 1999; 51:745-781. [PubMed: 10581329]

Paxinos, G.; Franklin, KBJ. The Mouse Brain in Stereotaxic Coordinates. 2nd. Academic Press; 2001.

Pommier B, Beslot F, Simon A, Pophillat M, Matsui T, Dauge V, Roques BP, Noble F. Deletion of CCK2 receptor in mice results in an upregulation of the endogenous opioid system. J Neurosci. 2002; 22:2005-2011. [PubMed: 11880531]

Ramos A. Animal models of anxiety: do I need multiple tests? Trends Pharmacol Sci. 2008; 29(10): 493-8. [PubMed: 18755516]

Raud S, Innos J, Abramov U, Reimets A, Koks S, Soosaar A, Matsui T, Vasar E. Targeted invalidation of CCK2 receptor gene induces anxiolytic-like action in light-dark exploration, but not in fear conditioning test. Psychopharmacology (Berl). 2005; 181:347-357. [PubMed: 15830228]

Renard CE, Dailly E, David DJ, Hascoet M, Bourin M. Monoamine metabolism changes following the mouse forced swimming test but not the tail suspension test. Fundam Clin Pharmacol. 2003; 17:449-455. [PubMed: 12914547]

Rotzinger S, Lovejoy DA, Tan LA. Behavioral effects of neuropeptides in rodent models of depression and anxiety. Peptides. 2010; 31:736-756. [PubMed: 20026211]

Schiffmann SN, Vanderhaeghen JJ. Distribution of cells containing mRNA encoding cholecystokinin in the rat central nervous system. J Comp Neurol. 1991; 304:219-233. [PubMed: 2016418] 
Sherrin T, Todorovic C, Zeyda T, Tan CH, Wong PT, Zhu YZ, Spiess J. Chronic stimulation of corticotropin-releasing factor receptor 1 enhances the anxiogenic response of the cholecystokinin system. Mol Psychiatry. 2009; 14:291-307. [PubMed: 18195718]

Shindo S, Yoshioka N. Polymorphisms of the cholecystokinin gene promoter region in suicide victims in Japan. Forensic Sci Int. 2005; 150:85-90. [PubMed: 15837012]

Turri MG, Datta SR, DeFries J, Henderson ND, Flint J. QTL analysis identifies multiple behavioral dimensions in ethological tests of anxiety in laboratory mice. Curr Biol. 2001; 11(10):725-34. [PubMed: 11378382]

Valverde O, Roques BP. Cholecystokinin modulates the aversive component of morphine withdrawal syndrome in rats. Neurosci Lett. 1998; 244:37-40. [PubMed: 9578139]

van Gaalen MM, Steckler T. Behavioural analysis of four mouse strains in an anxiety test battery. Behav Brain Res. 2000; 115(1):95-106. [PubMed: 10996412]

Voikar V, Vasar E, Rauvala H. Behavioral alterations induced by repeated testing in C57BL/6J and 129S2/Sv mice: implications for phenotyping screens. Genes Brain Behav. 2004; 3:27-38. [PubMed: 14960013]

Wang H, Spiess J, Wong PT, Zhu YZ. Blockade of CRF1 and CCK2 receptors attenuated the elevated anxiety-like behavior induced by immobilization stress. Pharmacol Biochem Behav. 2011; 98:362-368. [PubMed: 21295058]

Zolotukhin S, Potter M, Zolotukhin I, Sakai Y, Loiler S, Fraites TJ Jr, Chiodo VA, Phillipsberg T, Muzyczka N, Hauswirth WW, Flotte TR, Byrne BJ, Snyder RO. Production and purification of serotype 1, 2, and 5 recombinant adeno-associated viral vectors. Methods. 2002; 28:158-167. [PubMed: 12413414] 


\section{Del Boca et al, Highlights}

- Cholecystokinin (CCK) was knocked-down in the baso-lateral amygdala using a shRNA.

- Amygdalar CCK knock-down reduced anxiety-like behaviors in the elevated plus maze.

- Amygdalar CCK knock-down decreased depressive-like behaviors in the forced swim. 
A

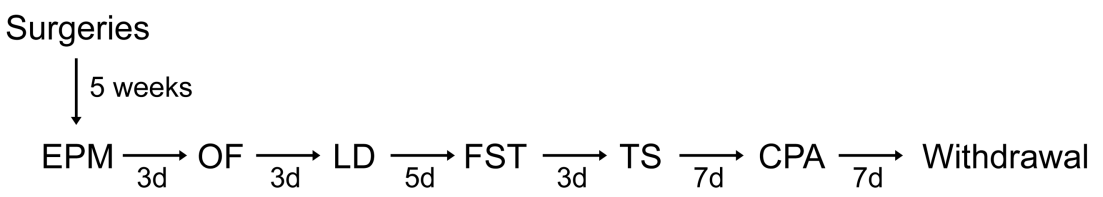

B

$$
\begin{aligned}
& \text { Surgeries } \\
& \qquad \begin{array}{l}
5 \text { weeks } \\
\text { EPM } \underset{5 \mathrm{~d}}{\longrightarrow} \text { FST } \underset{7 \mathrm{~d}}{\longrightarrow} \text { CPA }
\end{array}
\end{aligned}
$$

Figure 1. Behavioral testing protocol to evaluate effects of CCK knock-down in the mouse BLA using two independent mouse cohorts

(A) Cohort 1. (B) Cohort 2 Abbreviations: EPM, Elevated Plus-Maze; OF, Open Field; LD, Light/Dark box; FST, Forced Swim Test; CPA, Naloxone induced-Conditioned Place Aversion; Naloxone precipitated-Withdrawal; d, days. 

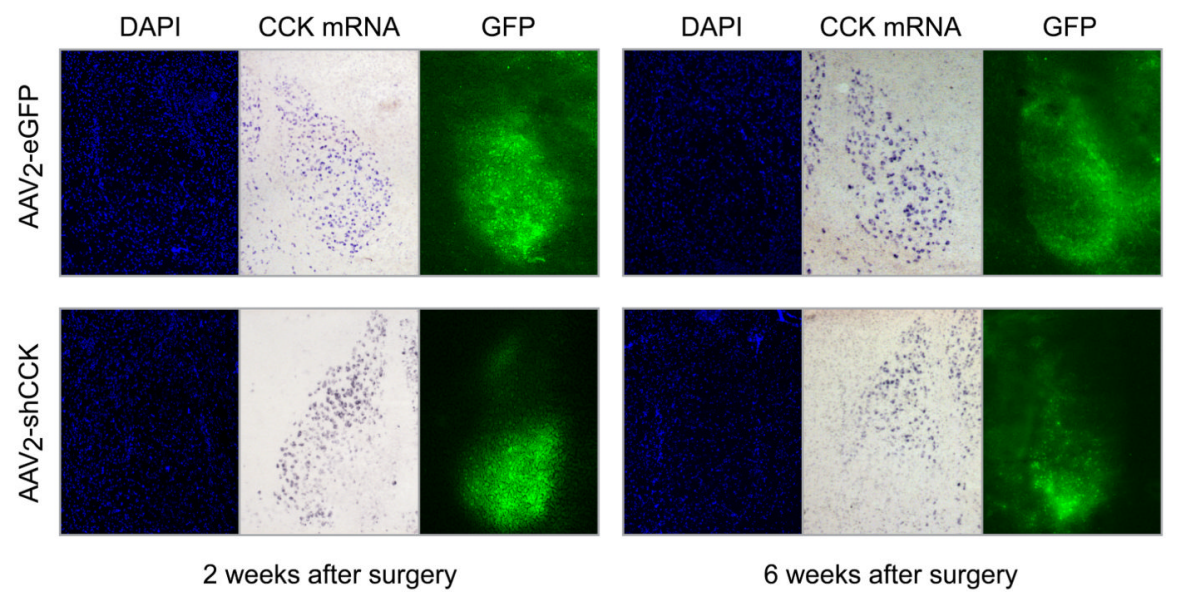

Figure 2. $\mathrm{AAV}_{2}$-shCCK injections in the BLA reduces CCK mRNA levels

Representative brain microsections showing DAPI staining (left), dig-labeled CCK mRNA (middle), and eGFP expression (right) of mice unilaterally injected into BLA with either $\mathrm{AAV}_{2}$-eGFP (top panels) or $\mathrm{AAV}_{2}$-shCCK (bottom panels) viral vectors $\left(1.5 \mu 1,3 \times 10^{11} \mathrm{vg} /\right.$ $\mathrm{ml})$. Mice were sacrificed for tissue collection either 2 or 6 weeks following surgery. CCK mRNA downregulation is observed in $\mathrm{AAV}_{2}$-shCCK but not $\mathrm{AAV}_{2}$-eGFP control samples, in an area overlapping maximal viral expression. 

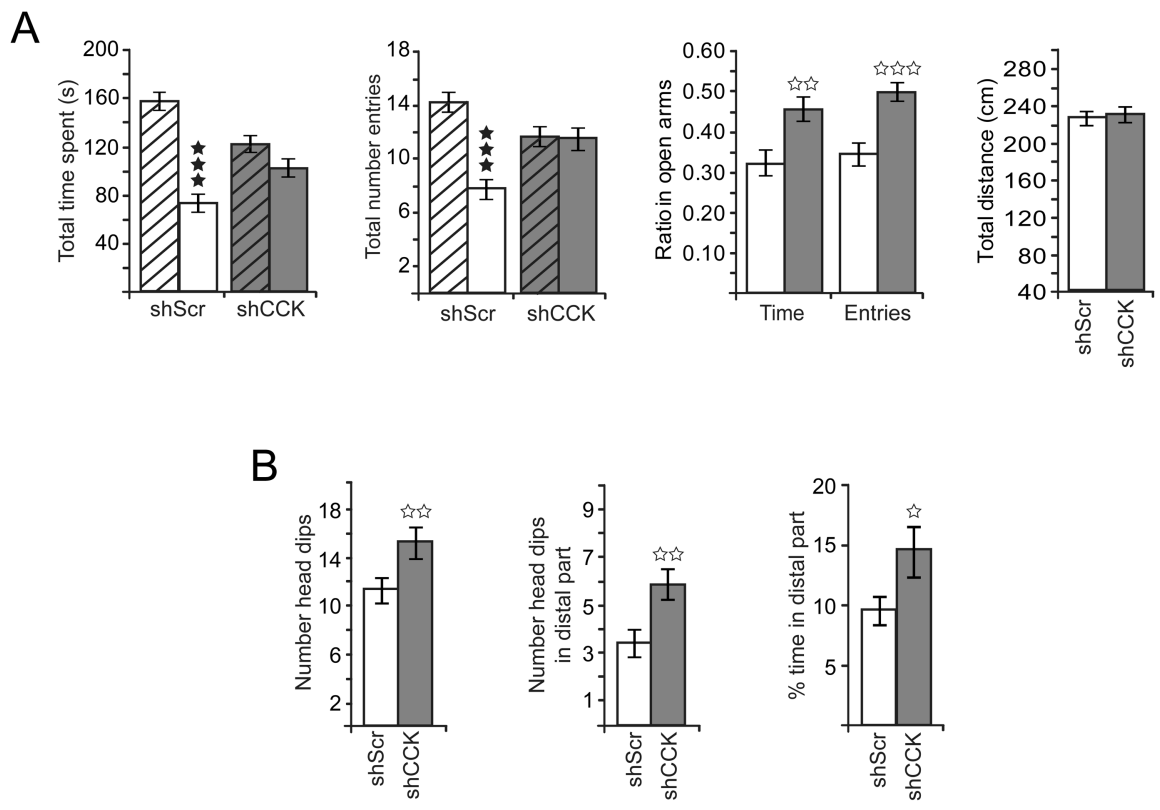

Figure 3. CCK knockdown in mouse BLA reduces levels of anxiety in the elevated plus-maze Mice were bilaterally injected into BLA with either $\mathrm{AAV}_{2}$-shCCK (grey bars) or $\mathrm{AAV}_{2-}$ shScramble (white bars) viral vectors and tested in the EPM. (A) Anxiety-like behavior. $\mathrm{AAV}_{2}$-shCCK-injected mice showed lower levels of anxiety, as indicated by time spent and number of entries in open (full bars) vs closed (striped bars) arms. Ratios of the time spent in and the number of entries to the open arms ((open arm)/(open arm + closed arms)) and total distance travelled are also shown. (B) Risk-taking behavior. $\mathrm{AAV}_{2}$-shCCK-injected mice showed increased risk-taking behavior as determined by number of total head dips in the open arms, number of head dips from the distal part of the open arms (last 1/3 of the arm) and percentage time spent in the distal part of the open arms. All results are expressed as mean \pm SEM. Black stars, comparisons between arms; White stars, comparisons between

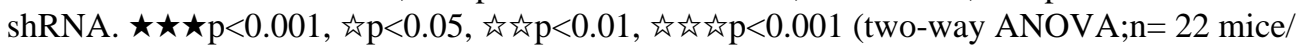
group). 
A

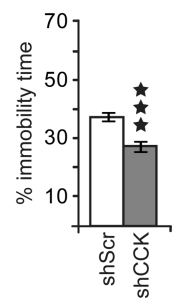

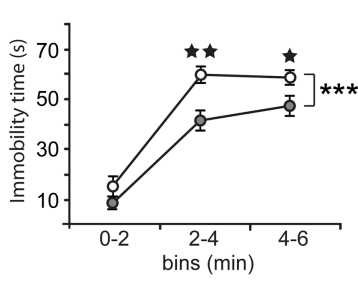

day 1

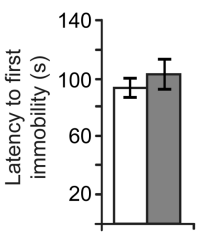

B

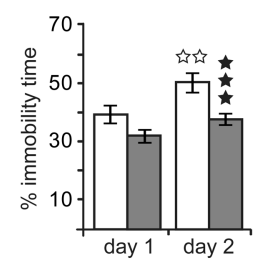

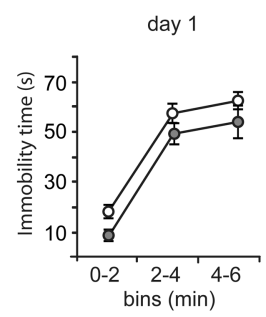

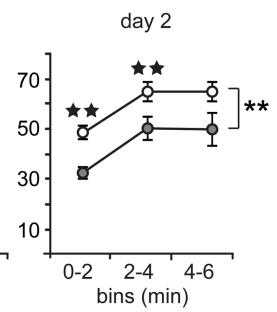

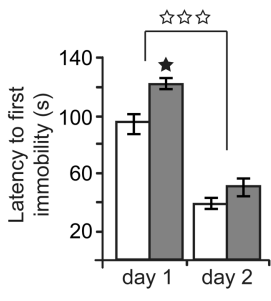

Figure 4. CCK knockdown in mouse BLA reduces despair-like behavior in the forced swim test Mice were bilaterally injected into BLA with either $\mathrm{AAV}_{2}$-shCCK (grey bars and circles) or $\mathrm{AAV}_{2}$-shScramble (white bars and circles) viral vectors and tested in the FST. AAV $2^{-}$ shCCK-injected mice showed reduced despair-like behavior in both Cohort 1 (A) and Cohort 2 (B) as evaluated by percentage of immobility time during the 6 min test, time course of immobility in 2 min bins (seconds) and latency to the first immobility episode (seconds). For Cohort 2, data from repeated FST on day 1 and 2 are shown. All results are expressed as mean \pm SEM. Black stars, individual comparisons between shRNA; asterisks, global time courses comparisons between shRNAs; white stars, comparisons between days. $\star \mathrm{p}<0.05, \star \star \mathrm{p}<0.01, \star \star \star \mathrm{p}<0.001, * * \mathrm{p}<0.01, * * * \mathrm{p}<0.001$, 认为 $\mathrm{p}<0.01$, 记云认 $\mathrm{p}<0.001$ (one- and two-way ANOVA; $\mathrm{n}=10-11$ mice/group in cohort 1, 9-10 mice/group in cohort 2). 


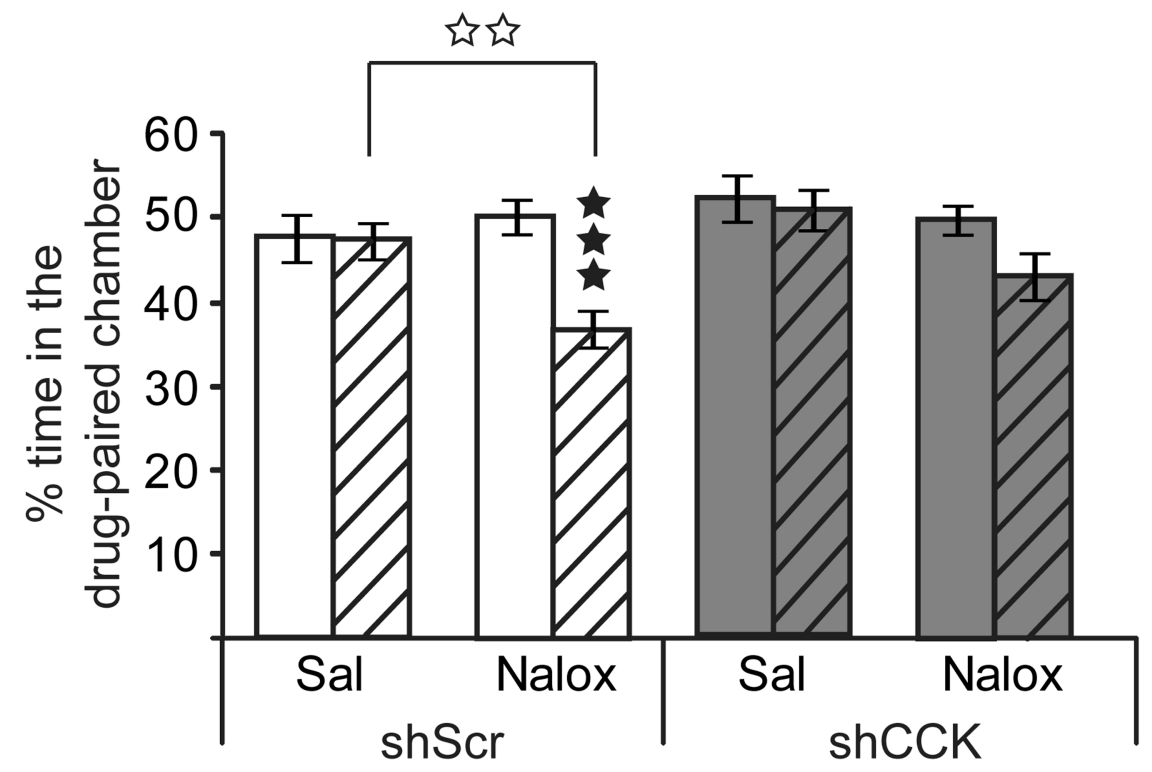

Figure 5. CCK knockdown in mouse BLA reduces naloxone-induced place aversion (CPA) Mice were bilaterally injected into BLA with either $\mathrm{AAV}_{2}$-shCCK (grey bars) or $\mathrm{AAV}_{2-}$ shScramble (white bars) viral vectors. Naloxone place conditioning is shown as percentage of time spent in the drug-paired compartment during pre- (full bars) and post-conditioning (striped bars) sessions. Post-hoc analyses show that naloxone produced significant CPA in $\mathrm{AAV}_{2}$-shScramble but not in $\mathrm{AAV}_{2}$-shCCK mice. Results are expressed as mean $\pm \mathrm{SEM}$. Black stars, individual comparisons between sessions; white stars, individual comparisons

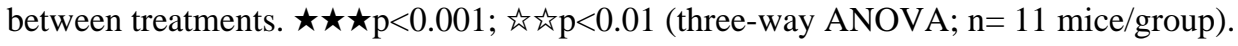




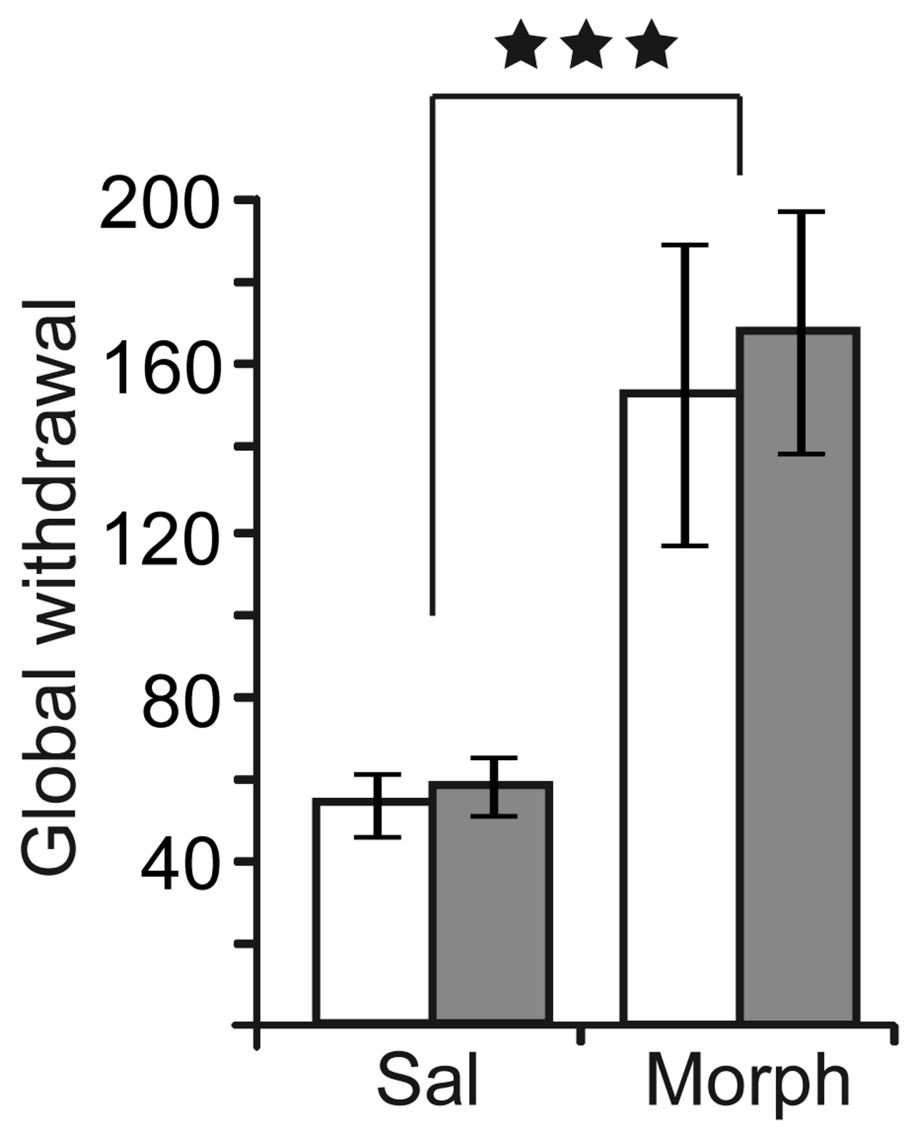

Figure 6. CCK knockdown in mouse BLA does not modify naloxone-precipitated withdrawal after chronic morphine treatment

Mice were bilaterally injected into BLA with either $\mathrm{AAV}_{2}$-shCCK (grey bars) or $\mathrm{AAV}_{2}$ shScramble (white bars) viral vectors, subjected to a chronic morphine regimen and naloxone-precipitated withdrawal. The global withdrawal score is shown ((horizontal activity + rearings + scratches + genital licks + head shakes + wet dog shakes + grooming $) \times$ $0.5+$ (jumps + front paw tremors + sniffings $) \times 1+$ (body tremors + ptosis + teeth chattering + piloerection $\times 1$ ), expressed as mean \pm SEM. Naloxone-precipitated withdrawal did not differ between the two groups. $\star \star \star \mathrm{p}<0.01$ (two-way ANOVA; $\mathrm{n}=4$ mice/group). 
A

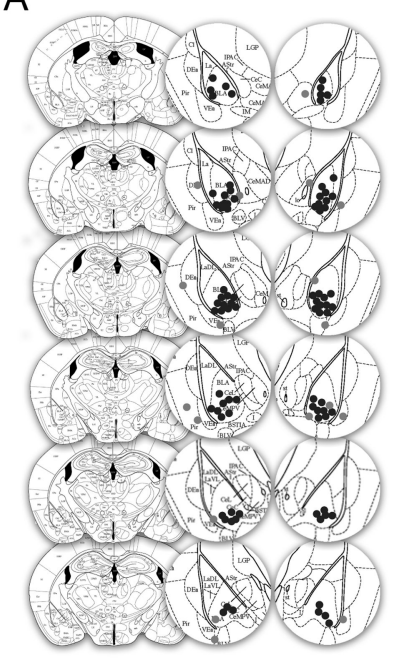

B
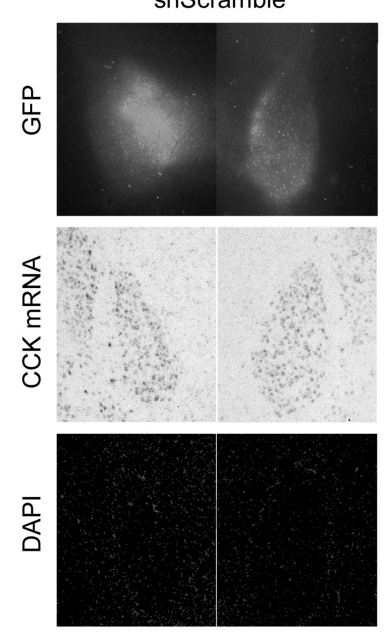
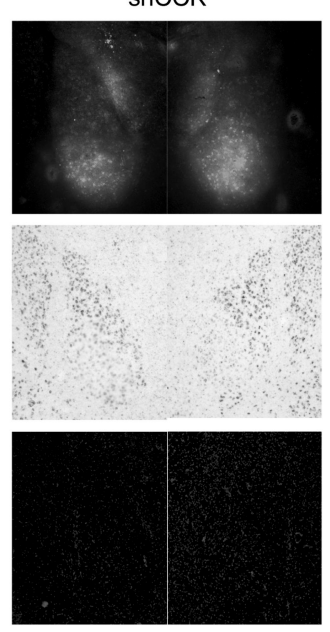

C
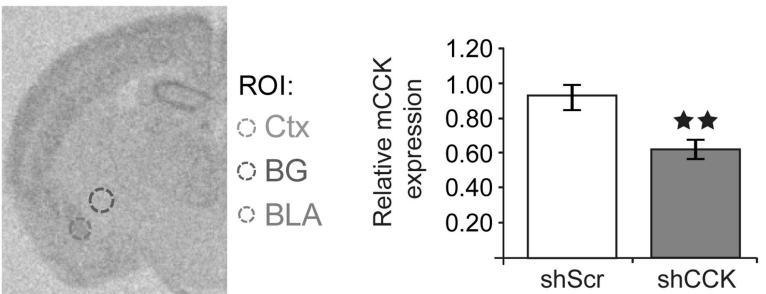

Figure 7. Quantitative validation of $\mathrm{AAV}_{2}$-shRNA-CCK knockdown into the mouse BLA Mice were sacrificed for tissue collection 9 weeks after surgery. (A) Images from the Mouse Brain Atlas of Paxinos and Franklin (2001) showing histological reconstruction of injection sites into BLA. Black circles: correct injections of shCCK and shScramble vectors; red circles: .misplaced injections. (B) Representative brain sections showing eGFP expression (up), dig-labeled CCK mRNA (middle) and DAPI staining (bottom) from mice bilaterally injected into BLA with either $\mathrm{AAV}_{2}$-shScramble (left), or $\mathrm{AAV}_{2}$-shCCK (right) viral vectors $\left(1.5 \mu \mathrm{l}, 3 \times 10^{11} \mathrm{vg} / \mathrm{ml}\right)$. As in Figure 2, lower CCK mRNA is observed at the site of maximal viral expression in shCCK, but not shScramble, samples. (C) Left; representative autoradiographic image of a brain section processed for radioactive-ISH showing regions of interest (ROI) used in the quantification (Ctx, RAS cortex region; BG, Striatum

BackGround; BLA, BasoLateral nucleus of the Amygdala). Right; quantification performed using a calibration curve of $\mathrm{C}^{14}$ standards (ARC0146; American Radiolabeled Chemicals) and theImageJ software. A rodbard non-lineal regression function was used to convert grey levelsinto counts of radioactivity (nCi/mg). CCK mRNA expression is significantly reduced in theBLA of $\mathrm{AAV}_{2}$-shCCK treated animals (grey bar) compared to their AAV2-shScramble controls (white bar). Results are expressed in normalized values obtained from meanradioactive measures [(BLA - Striatum background)/(RAS Cortex - Striatum background)] \pm SEM. $\star \star \mathrm{p}<0.01$ (Unpaired Student's t-test; $\mathrm{n}=5$ mice/condition). 


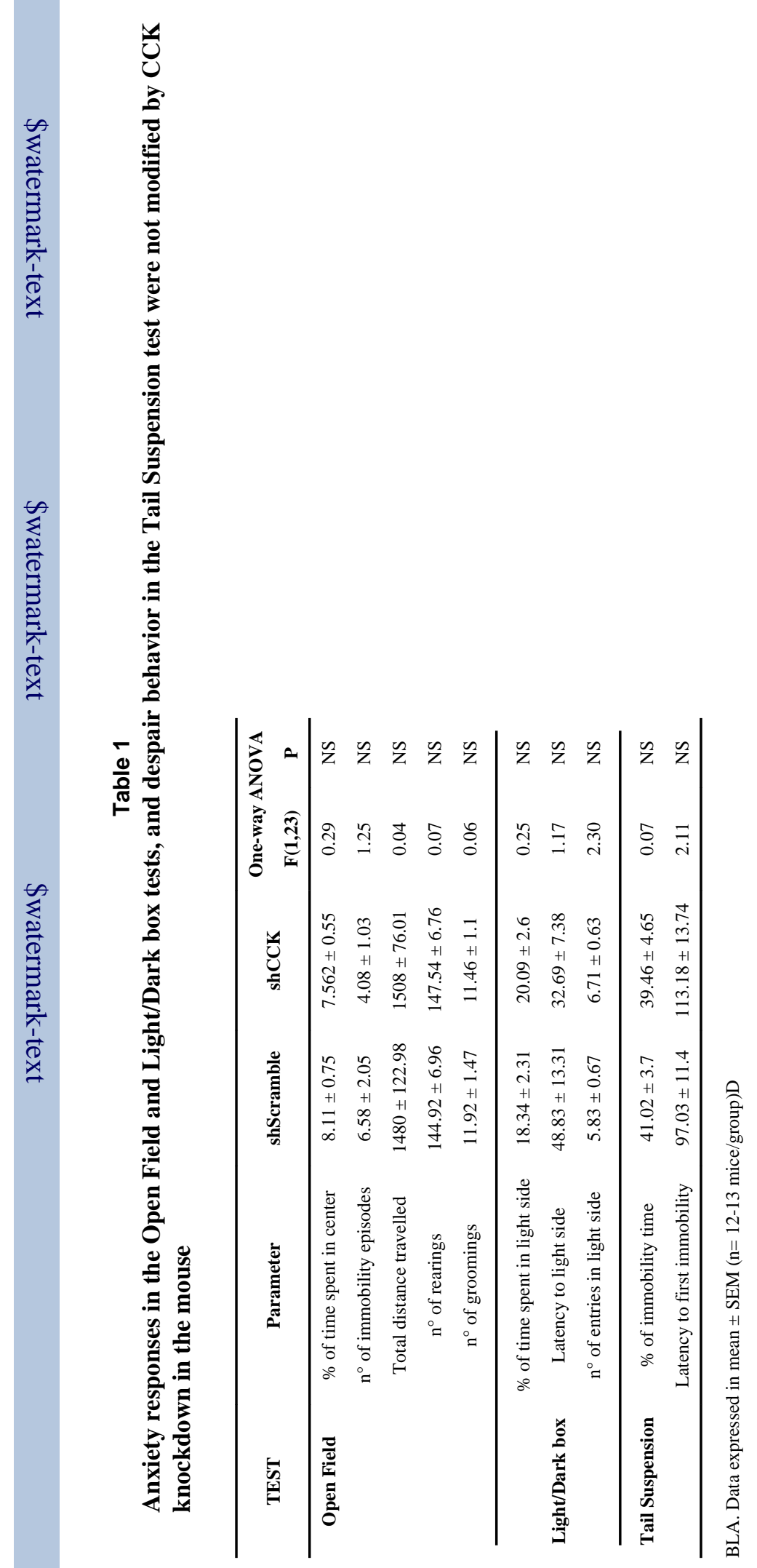


